ON THE RECORD

"Cloning a human

being is nonsense.

Briefly, it is not ethical,

it is not safe at all, and it's technically impossible."

South Korean stem-cell pioneer Woo SukHwang responds to fears about human cloning.

'CWe won't be asking passengers to leave a sample and we won't be carrying a resident sheep at the back of the bus."

Andrew $D$ yer, managing director of Stagecoach South, UK, explains plans to use sheep urine to reduce exhaust emissions on its buses.

\section{SCORECARD}

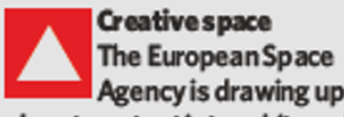
plans to put artinto orbit, andis carvas sing ideas on how to bring high culture to the Space Station. The results could truly be out of this world.

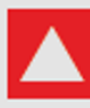

Rub a chicken

Atlast - it's possible to peta henonline.Stroking a model chicken sends signals winging across the Internet to a birdwearing a specialjacket. The coatlets the henfeel the caresses as if they were real. It's enough to cure any fowl mood.

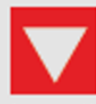

In-flight chitchat Plans to allow mobile phone calls on planes have riled radioastronomers, who fear that the inane chatter will drown out the faint signals from the stars.

\section{DATAPOINT}

Percentage of Americans who rate the quality of the environment as 'good' or 'excellent'.

\section{Democrats $27 \%$}

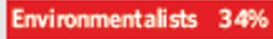

\title{
German tobacco papers reveal lump sums for health experts
}

MUNICH

The tobacco industry is now notorious for its attempts to influence the public-health sector in recent decades. Now an analysis of millions of industry documents reveals just how successful companies were at en listing Germany's top health experts in tobacco-friendly studies - a tactic that many believe is responsible for the country's lax antismoking laws today.

International firms such as Philip Morris, R. J. Reynolds and Brown \& Williamson paid millions of deutschmarks in the 1980 s and 1990s to leading health experts such as Karl Uberla, who was then president of Germany's federal public-health department, and Jürgen von Troschke, head of the German Coordinating Agency for Public Health, based at Freiburg University. The allegations were published last week in the news magazine Der Spiegel.

The study was commissioned by the German Cancer Research Center (DKFZ) in Heidelberg, which asked sociologist Dietmar Jazbinsek to search Internet archives of more than $\mathbf{4 0}$ million documents that a US court forced the tobacco industry to make public in 1998. He was continuing work started by the US physician Norbert Hirschhorn, who published the results of a scan of 600 documents in 2000 (N. Hirschhorn Tobacco Control 9, 242-248; 2000).

Jazbinsek identified the country's 15 most prominent public-health experts and searched the tobacco archives using various spellings of their names. He discovered that at least four of the 15 had received large sums from industry, mostly through research bodies, to produce reports on the risks and benefits of smoking.

Martina Pötschke-Langer, head of the cancer prevention unit at the DKFZ, says she is stunned by the size of the scandal. "It seems as if hundreds of German researchers and scientific societies have been involved," she says.

The biggest sum went to Uberla, who got DM1.6 million (US\$1 million) in 1982 from a German tobacco industry association to do a study into the risk of passive smoking. The work, published in the early 1990s in the nonpeer-reviewed, German-language journal Münchener Medizinische Wochenschrift, played down the risk, according to cancer researchers.

Von Troschke received DM40,000 in the same year for a literature review about smoker motivation. In subsequent talks and publications he frequently referred to the "psychosocial benefits of smoking". In a popular book in 1987, von Troschke warned of discrimination against smokers. He described a "bloodthirsty $\operatorname{mood}^{x}$ in the German public, which he compared to the Nazi's persecution of Jews.

The other two experts named in the report are Johannes Siegrist, director of the Institute of Medical Sociology at the University of Düsseldorf, and Johannes Gostomzyk, a researcher at the Augsburg health authority. Siegrist admitted to Nature that he received three payments, but he says that his studies were independent and that he feels deceived by the way the industry used his results. Uberla and von Troschke admitted to Der Spiegel that payments were made, although both insist that the funding did not bias their studies. Neither they nor Gostomzyk responded to Nature's requests for an interview.

There is no suggestion that the four experts made up or manipulated scientific data. Most of their studies could be classified as 'soft' science, relying on the presentation of different arguments, says Jazbinsek. But he says they all tended towards views favoured by industry. "It is absolutely mad that top public-health experts - of all people - accept funds from the tobacco industry, Jazbinsek says. "These collaborations have been good for their careers."

Many, including Pötschke-Langer, believe that the stance of those such as Uberla is part of the reason that effective non-smoking legislation was not implemented in Germany until recently. Although the country has ratified the World Health Organization's Framework Convention on Tobacco Control, which came into force in February, its antismoking legislation lags far behind that of the United States, Canada and many European countries.

Ironically, the DKFZ itself accepted grants from the tobacco industry, until a new director ended the practice in 1982 . Some payments to scientists continue, such as the Philip Morris research prize, for example. But scientists at the DKFZ are urgently calling for an ethical code that will oblige scientists and health researchers - and creative artists - to reject all sponsorship from the tobacco industry. Quirin Schiermeier 